\section{Calcified pseudotumoural mediastinal amyloidosis}

\author{
M C F Jenkins, $M$ Potter
}

\begin{abstract}
A patient with a plasma cell neoplasm presented with progressive major airways obstruction from a large mediastinal calcified amyloid tumour.
\end{abstract}

Pseudotumoural nodular mediastinal amyloidosis is rare and few cases have been reported. ${ }^{1-3}$ This is the first reported case in which amyloid was confined to the mediastinum.

\section{Case report}

A 53 year old woman presented in 1986 with signs of progressive major airways obstruction. An extramedullary plasmacytoma affecting mediastinal and cervical lymph nodes had been diagnosed 13 years previously after histological examination of an excised cervical node. At that time a chest radiograph showed a massive noncalcified mediastinal shadow consistent with lymphadenopathy and the serum contained an IgG paraprotein of lambda subtype (measuring $54 \mathrm{~g} / \mathrm{l}$ ). Serum calcium and phosphate concentrations were normal and Bence-Jones protein was not present in urine. Multiple myeloma had been excluded by a normal radiological skeletal survey. Initial treatment with three doses of vinblastine $10 \mathrm{mg}$ and cyclophosphamide $40 \mathrm{mg}$ daily for 28 days and prednisolone $40 \mathrm{mg}$ daily for 14 days was unsuccessful. Treatment was changed to mediastinal radiotherapy plus melphalan $12.5 \mathrm{mg} /$ day and prednisolone $100 \mathrm{mg} /$ day in four week cycles. After three years there was complete symptomatic relief; a repeat chest radiograph and the bone marrow aspirate were entirely normal,

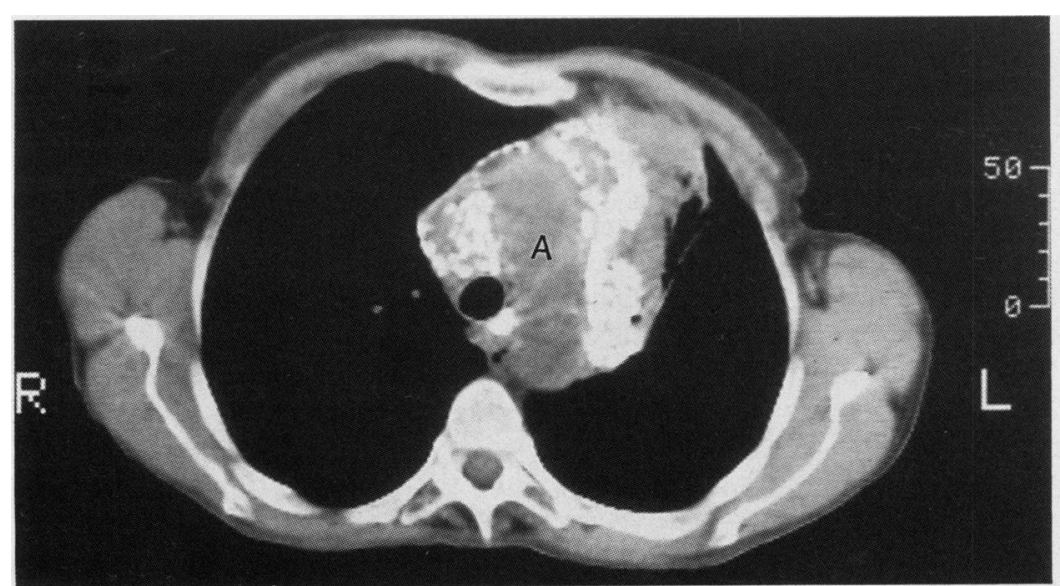

Computed tomogram of chest (level of 4th thoracic vertebra) showing calcified mass surrounding lower trachea and aortic arch $(A)$. though the serum IgG concentration was persistently raised at $30 \mathrm{~g} / 1$.

A chest radiograph when she presented again showed a large calcified mediastinal mass, which was confirmed by computed tomography (figure). The serum calcium concentration was still normal. At bronchoscopy extrinsic compression and obstruction of the left upper lobe bronchus were seen. Endobronchial biopsy specimens and a subsequent wedge biopsy specimen (measuring $1.7 \times 0.8 \times 0.5 \mathrm{~cm}$ ) showed only non-specific inflammatory changes with fibrosis. Two months after these investigations (still without a diagnosis for the mass) the patient developed acute major airways obstruction and died of respiratory failure.

At necropsy a large nodular mass measuring $8 \mathrm{~cm}$ in maximum dimension was found to encircle the aortic arch, lower trachea, and left main bronchus causing airways obstruction. It was extremely hard with extensive calcification. The cut surface was homogeneous and pale grey with small deposits of anthracite, consistent with an origin from mediastinal lymph nodes. Histological, histochemical, and electron microscopic examination showed that the mass consisted of AL amyloid. Amyloid was not present elsewhere in the body (brain, lung, heart, spleen, liver, thyroid gland, kidney, and adrenal gland were sampled). Neoplastic plasma cells were identified in paratracheal lymph nodes. The cervical lymph node removed in 1973 did not contain amyloid. Histochemical examination showed monoclonality for IgG lambda in lymph nodes obtained in 1973 and 1987.

\section{Discussion}

Extramedullary plasmacytomas are rare tumours of mature plasma cells that arise in soft tissues. ${ }^{4}$ They must be distinguished from a soft tissue metastasis of multiple myeloma and from soft tissue invasion by an adjacent intramedullary plasma cell tumour (that is, multiple myeloma and solitary myeloma of bone), which are histologically identical. In such cases, however, a radiological skeletal survey would show abnormalities. In contrast to multiple myeloma, the prognosis for extramedullary plasmacytoma is relatively good with a median survival of more than 10 years. ${ }^{4} \mathrm{~A}$ few extramedullary plasmaytomas contain amyloid, ${ }^{45}$ but the original tumour of our patient did not. We speculate that its subsequent formation may have been triggered by a treatment induced mutation in neoplastic plasma cells.

Nodular deposits of intrathoracic amyloid ("amyloid pseudotumours") are rare lesions that usually arise in lung parenchyma. The amyloid may be either confined to one anatomical site or systemic. Only three previous cases of pseudotumoural mediastinal amyloidosis have been reported in the English literature (table) ${ }^{1-3}$ The present case is the first in which amyloid was entirely confined to the mediastinum. Of the two major classes of amyloid-AL type (derived from immuno- 
Cases of pseudotumoural mediastinal amyloidosis

\begin{tabular}{lllllllll}
\hline Reference & $\begin{array}{c}\text { Age } \\
(y)\end{array}$ & Sex & $\begin{array}{c}\text { Maximum } \\
\text { size }(\mathrm{cm})\end{array}$ & Type & Distribution & $\begin{array}{l}\text { Lung } \\
\text { disease }\end{array}$ & $\begin{array}{l}\text { Calcifi- } \\
\text { cation }\end{array}$ & Other diseases \\
\hline Onoss $^{1}$ & 49 & M & $8 \cdot 5$ & NK & Systemic & NK & 0 & Inflammatory bone mass \\
Melato $^{2}$ & 66 & F & 10 & AL & Systemic & + & 0 & Multiple myeloma \\
Shaw $^{3}$ & 67 & F & NK & AL & Systemic & + & + & Primary amyloidosis \\
Present case $^{6}$ & 69 & F & 8 & AL & Localised & 0 & + & Extramedullary plasmacytoma \\
\hline
\end{tabular}

NK - Not known.

cytes) and AA type (reactive or secondary amyloid)-localised deposits are probably always of the AL type 5 and can be diagnosed with certainty only by biopsy. Complete resection is potentially curable; this would not have been possible in our patient, though in retrospect partial endobronchial resection may have given symptomatic relief. The radiological manifestations of intrathoracic amyloidosis are non-specific but calcification is seen with surprising frequency; up to $29 \%$ of cases of amyloidosis localised to the lower respiratory tract show calcification. ${ }^{6} \mathrm{~W}$ ilson et al ${ }^{7}$ reviewed the radiological features of intrathoracic amyloidosis and drew attention to its presentation as "massive calcific lymph node enlargement." In both papers ${ }^{67}$ the authors remarked on the ease with which a conclusive diagnosis could be made by biopsy. In the present case calcification prevented successful biopsy on two separate attempts, which included a wedge biopsy.

Amyloid should be considered in the dif- ferential diagnosis of a large mediastinal mass, especially if calcification is present and particularly if the patient has a plasma cell neoplasm. We would like to thank Dr R R Slade of Southmead Hospital,
Bristol, for permitting us to publish this case, Professor D H Wright of Southampton University for reviewing the cervical lymph node histology, and Dr N Ibrahim of Frenchay Hospital, Bristol, for his helpful comments.

1 Osnoss $\mathrm{KL}$, Hareli DD. Isolated mediastinal mass in primary amyloidosis. Chest 1980;78:786-8.

2 Melato M, Antonutto G, Falconieri G, Manconi R. Massive amyloidosis of mediastinal lymph nodes in a patient with multiple myeloma. Thorax 1983;38:151-2.

3 Shaw P, Grossman R, Fernandes BJ. Nodular mediastinal amyloidosis. Hum Pathol 1984;15:1183-5.

4 Wiltshaw E. The natural history of extramedullary plasmacytoma and its relation to solitary myeloma of bone and myelomatosis. Medicine 1976;55:217-38.

5 Glenner GG. Amyloid deposits and amyloidosis. $N$ Engl J Med 1980;302:1333-43.

6 Rubinow A, Celli BR, Cohen AS, Rigden BG, Brody JS. Localised amyloidosis of the lower respiratory tract. $\mathbf{A m}$ Rev Respir Dis 1978;118:603-11.

7 Wilson SR, Sanders DE, Delarue NC. Intrathoracic manifestations of amyloid disease. Radiology 1976;120: 283-9. 